\title{
КОРПОРАТИВНЫЕ ПРЕСТУПЛЕНИЯ И ИХ ТИПОЛОГИЯ
}

\author{
(C) 2021 Дуболазова Юлия Андреевна \\ кандидат экономических наук, доцент \\ Санкт-Петербургский политехнический университет Петра Великого, Россия, Санкт-Петербург \\ E-mail: dubolazova_yua@spbstu.ru
}

(c) 2021 Акласова Анастасия Алексеевна

студент, Высшая инженерно-экономическая школа

Санкт-Петербургский политехнический университет Петра Великого, Россия, Санкт-Петербург

E-mail: aklasova99@mail.ru

\section{(c) 2021 Кранина Анна Дмитриевна}

Санкт-Петербургский национальный исследовательский университет информационных технологий, механики и оптики, Россия, Санкт-Петербург

E-mail: annakranina@gmail.com

С помощью методов логического, статистического, сравнительного и сопоставительного анализа в данной статье были рассмотрены теоретические и практические аспекты корпоративных преступлений. Также были сопоставлены понятия корпоративной преступности, данные различными авторами. Проведен анализ сравнения корпоративной преступности в Российской Федерации и за рубежом. Были проанализированы практики предотвращения и борьбы с корпоративной преступностью в России и в зарубежных странах. А также были разработаны основы борьбы с корпоративной преступностью, которые улучшат результативность противодействия данного рода преступности и уменьшат случаи ее возникновения.

Было выявлено, что одним из способов снижения доли корпоративных преступлений является установление благоприятного рабочего климата между сотрудниками компаний. Это будет первым шагом на пути к уменьшению у работников желания совершить корпоративное преступление. Также руководство компаний не должно забывать об организации качественной деятельности отдела экономической безопасности предприятия, потому что эффективная работа данной службы снизит риски и угрозы совершения корпоративных преступлений на предприятии. Кроме того, одним из ключевых факторов является совершенствование уголовного законодательства, которое способствует ведению эффективной борьбы с корпоративными преступлениями.

Ключевые слова: корпоративная преступность, экономическая безопасность, экономические преступления, меры противодействия, корпоративное мошенничество, борьба с преступностью, беловоротничковая преступность

В современном мире экономические преступления уже давно стали обыденной частью человеческой жизни. Каждый день совершаются различные преступления в данной сфере. Это происходит настолько часто, что люди перестали этому удивляться и обращать свое внимание. Так МВД России насчитало ущерб от экономических преступлений в РФ за 2019 год на сумму 440 млрд. рублей.

Экономическая преступность является одним из самых распространенных видов преступлений. Причиной этому стало то, что здесь преступники за одно совершенное противозаконное деяние могут получить большое количество денежных средств. А это говорит о том, что данные преступления чаще всего совершаются с корыстным умыслом.

В уголовном законодательстве РФ сказано, что экономическое преступление - это виновно совершенное общественно опасное деяние, запрещенное Уголовным кодексом Российской Федерации (далее УК РФ) под угрозой наказания.

Различные авторы дают свои понятия экономической преступности. Все их можно считать правильными, но не все полными. Так П. С.Яни считает, что на самом деле четко сформулировать понятие экономической преступности достаточно сложно. А.М.Медведев говорит о том, что экономические преступления причиняют материальный ущерб ценностям и благам за 
счет посягательств на экономическую деятельность субъектов. А вот Л.В.Бертовский писал о понятии экономического преступления, опираясь на уголовный закон. От себя автор добавил, что данные преступления посягают на общественно-экономические отношения [1].

Экономические преступления имеют множество видов. Те, в свою очередь, имеют собственные признаки, а также методы борьбы с ними, которые индивидуальны почти для каждого вида. Одним из самых распространенных видов преступлений в экономической сфере является корпоративная преступность [2].

На сегодняшний день данной проблеме уделяется большое внимание. С каждым годом количество данных преступлений увеличивается.
Все больше компаний терпят убытки, сталкиваясь с этим явлением. От корпоративной преступности страдают не только предприятия, но и сама экономика в целом.

Множество авторов дают собственные определения корпоративной преступности. В чем-то эти понятия схожи, а в чем-то различны. Данные определения представлены на рисунке 1. Здесь видно, что авторы делают акцент на том, что корпоративные преступления совершаются лицами, которые имеют высокую руководящую должность. А преступления совершаются, либо ради личной наживы, либо для улучшения финансового состояния собственной компании. И естественно, авторы отмечают, что данная преступная деятельность совершается для получе-

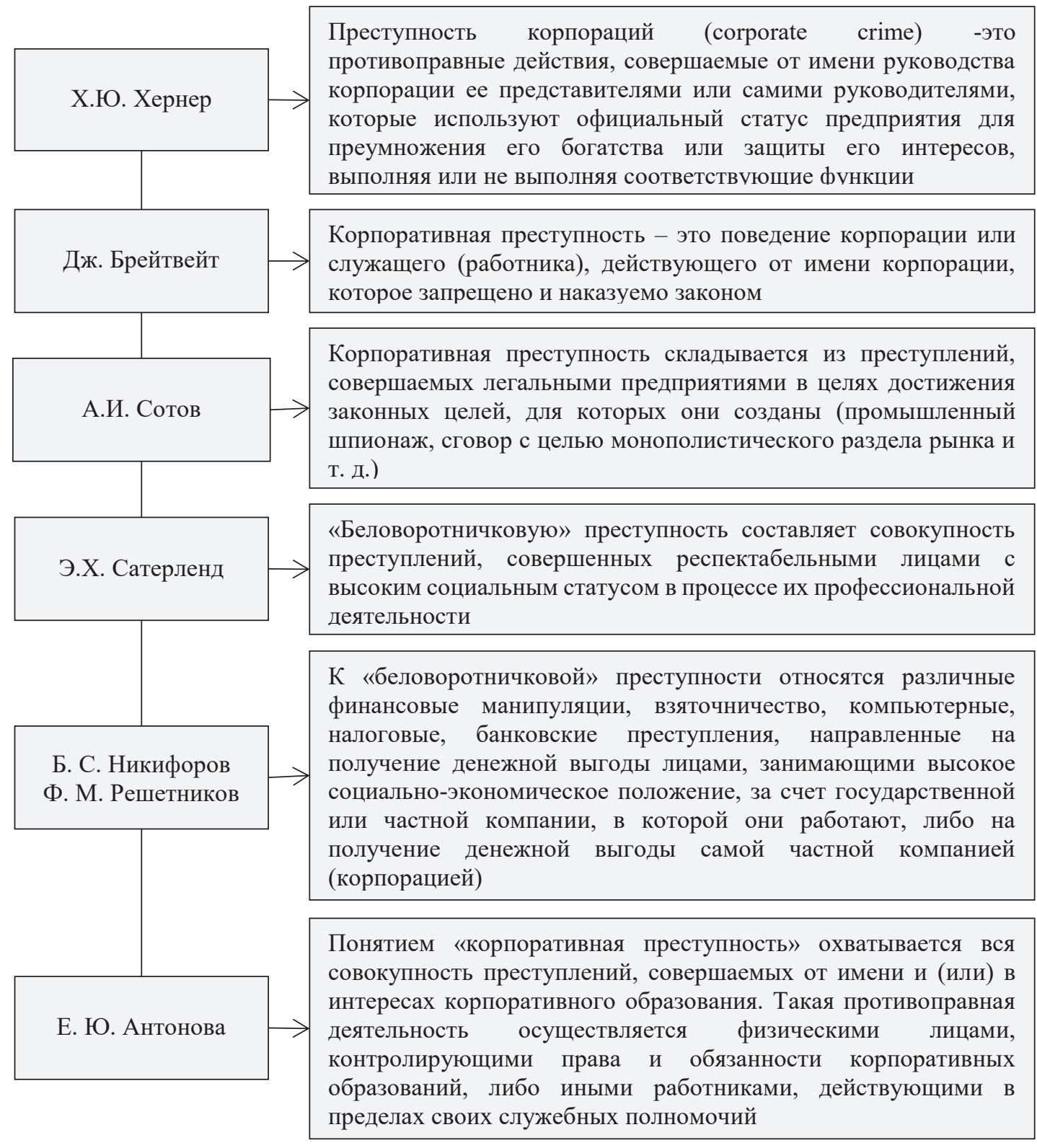

Рисунок 1. Понятия корпоративной преступности 
ния дохода, даже несмотря на то, что он нелегален. Сходств между понятиями достаточно много, даже несмотря на то, что авторы данных понятий являются, как и нашими соотечественниками, так и иностранцами.

Но все же имеется одна особенность. Можно заметить, что отечественные авторы говорят о том, что корпоративные преступления совершаются на благо компании. А вот зарубежные авторы об этом не упоминают. Исключением является только Х.Ю.Хернер, мнение которого совпадает с отечественными авторами. Можно лишь предположить, что это означает то, что за рубежом корпоративные преступления совершаются чаще для личной выгоды.

Таким образом, делаем вывод, что корпоративная преступность - это преследуемое по закону умышленное деяние, которое совершается должностными лицами, с целью увеличения своей материальной составляющей и/или для улучшения финансового состояния компании.

Теперь хотелось бы затронуть типологию корпоративной преступности. За последние годы количество типов данной преступной деятельности достаточно увеличилось. Сейчас эти типы развиваются, многие из них уже давно имеют свои подтипы. Это гораздо усложняет и без того трудную борьбу с корпоративной преступностью. Существующие типы можно увидеть на рисунке 2.

Самым распространенным типом является незаконное присвоение активов. Данный тип определяется как хищение, растрата, присвоение или приобретение права на чужое имущество путем обмана или злоупотребления доверием. Также незаконное присвоение активов имеет множество собственных типов. В первую очередь данный тип корпоративной преступности необходимо разделить на два вида - это махинации с наличными средствами, а также махинации с запасами и другими активами. В свою очередь данные виды делятся на подвиды. Это вы можете увидеть на рисунке 3.

Некоторые типы корпоративной преступности можно заменить всего одним понятием корпоративное мошенничество. Эта преступная деятельность имеет множество сложных схем, которые так непросто обнаружить. Последствия корпоративного мошенничества сильно бьют по экономической безопасности, как и самих предприятий, так и государства в целом. Довольно четкое определение данного вида мошенни-

\begin{tabular}{|c|c|}
\hline \multicolumn{2}{|r|}{ Корпоративная преступность } \\
\hline & Незаконное присвоение активов \\
\hline & Мошенничество при закупках товаров, работ, услуг \\
\hline & Манипулирование данными бухгалтерского учета \\
\hline & Налоговое мошенничество \\
\hline & Коррупция \\
\hline & Мошенничество, совершенное клиентом \\
\hline & Киберпреступления \\
\hline & Нарушение принципов делового поведения \\
\hline & Мошенничество в сфере управления персоналом \\
\hline & Легализация доходов, полученных преступным путем \\
\hline & Создание сотрудником параллельного бизнеса \\
\hline & Незаконное использование интеллектуальной собственности \\
\hline & Утечка конфиденциальной информации \\
\hline
\end{tabular}

Рисунок 2. Типы корпоративных преступлений 


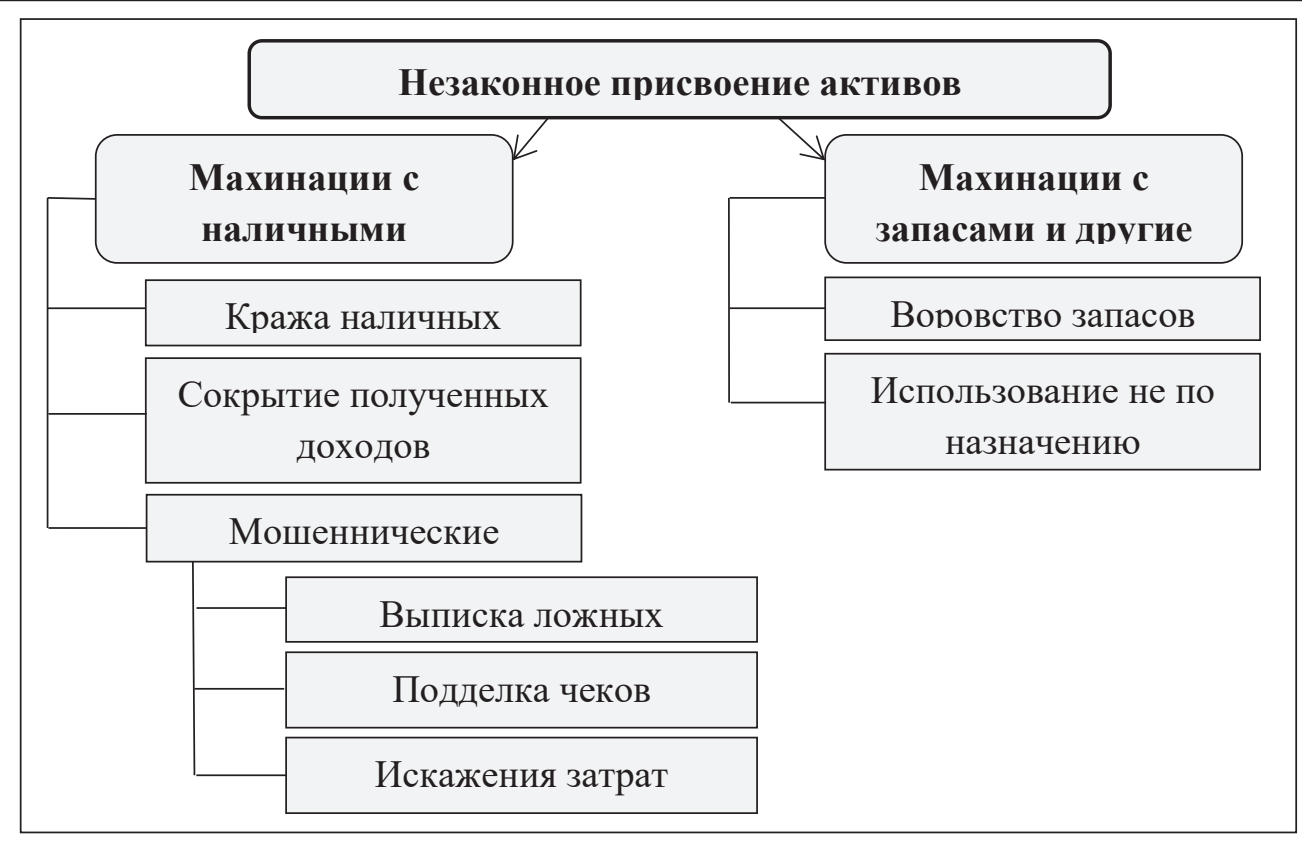

Рисунок 3. Типы незаконного присвоения активов

чества дано Международными стандартами аудита: корпоративное мошенничество - намеренное действие руководителей, управляющего персонала, работников, или третьих лиц, заключающееся в использовании обмана в целях получения незаконной либо неправомерной выгоды. Это понятие является более точным, нежели определение мошенничества, описанное в статье 159 УК РФ. Собственно, именно по этой статье рассматриваются дела, связанные с корпоративным мошенничеством, что и усложняет их раскрываемость, так как само по себе понятие мошенничество достаточно широкое. Именно поэтому здесь необходимо создать некое разделение корпоративного мошенничества от просто мошенничества. Возможно, именно это поможет более эффективно вести борьбу с корпоративным мошенничеством. Б.Э.Садыржанов, Н. Ю.Изварина, К. В. Климина, Я.А. Рябова, А.А. Гулый $[3,4,5]$.
Кроме того, стоит рассмотреть один из самых распространенных видов корпоративной преступности - коррупцию. Чаще всего именно о совершении этого типа можно услышать в новостных сводках или прочесть в газетах. Это связано с тем, что данные преступления совершают высокопоставленные должностные лица. Именно поэтому такие уголовные дела придаются громкой огласке. Но все же это не пугает других должностных лиц, и они позволяют себе совершить данное приступное деяние [6].

Коррупцию можно определить, как использование своего или чужого должностного положения, при помощи дачи и/или получения денежных средств, с целью получения личной выгоды. Этот тип корпоративной преступности делится на шесть подтипов. Их можно увидеть на рисунке 4.

Каждый тип корпоративной преступности имеет свои характерные черты и для каждого из

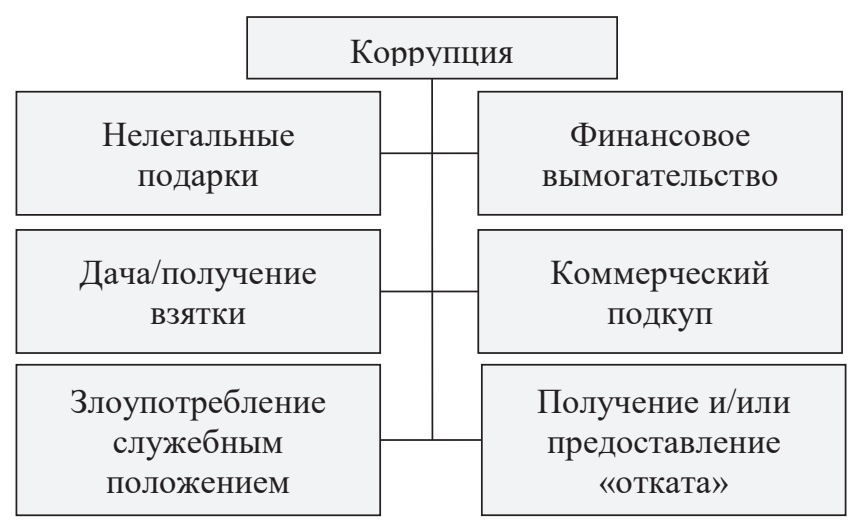

Рисунок 4. Составляющие коррупции 
них есть свои определенные методы борьбы. Но так уж выходит, что преступники все быстрее и быстрее улучшают свои навыки, придумывают все больше схем для удачного совершения корпоративных преступлений. Им все чаще удается обходить закон и удачно совершать свои злодеяния. А службам борьбы с корпоративной преступностью приходится делать все больше усилий для того чтобы обнаружить и предотвратить данную преступность. Они просто не успевают следить за появлением новых преступных схем. А это необходимо делать, для того чтобы совершенствовать старые и придумывать новые методы противодействия корпоративной преступности.

Навсегда избавиться от корпоративной преступности попросту невозможно. Люди и дальше будут совершать данные злодеяния. Но вопрос состоит только в том, смогут ли структуры борьбы научиться качественно и эффективно бороться с данной преступной деятельностью. Работа над этим должна быть непрерывной. Необходимо постоянно совершенствовать методы борьбы для того чтобы не отставать от преступников и их преступных схем. Это касается, как и отделов экономической безопасности на уровне компаний, так и государственных правоохранительных органов. Только совместная работа этих структур может дать положительный результат в борьбе с корпоративной преступностью.

Как уже говорилось, корпоративные преступления, как вид экономических преступлений, достаточно распространены по всему миру. По данным статистики за последние годы в России прослеживаеется нестабильная динамика экономических преступлений. Количество преступлений то уменьшается, то вновь растет, но все же остается примерно в одном диапозоне. Так в 2019 году в России было зарегистрировано 104927 дел, связанных с преступностью в экономической сфере, а в 2020 число преступлений увеличилось до 105480. Данные за последние семь лет можно увидеть на рисунке 5.

Что касается конкретно корпоративных преступлений, то компанией $\mathrm{PwC}$ был разработан рейтинг, в котором указано, сколько респондентов обнаружили на своем предприятии те или иные случаи корпоративной преступности. В данном рейтинге описаны случаи, как в России, так и по всему миру. Можно провести сравнение опыта России с остальным миром и обратить внимание на то, что абсолютным лидером среди типов корпоративной преступности по количеству случаев является незаконное присвоение активов, а вот меньше всего обнаруженных преступлений приходится на налоговое мошенничество. Все остальные пункты между собой не совпадают. Так, например, в России вторую строчку занимает взяточничество и коррупция, а вот в мире на этом же месте находится киберпреступность. Это связано с тем, что в Российской Федерации борьба с коррупцией только начинает усиливаться, в то время как в мире этот вопрос решается эффективной и слаженной

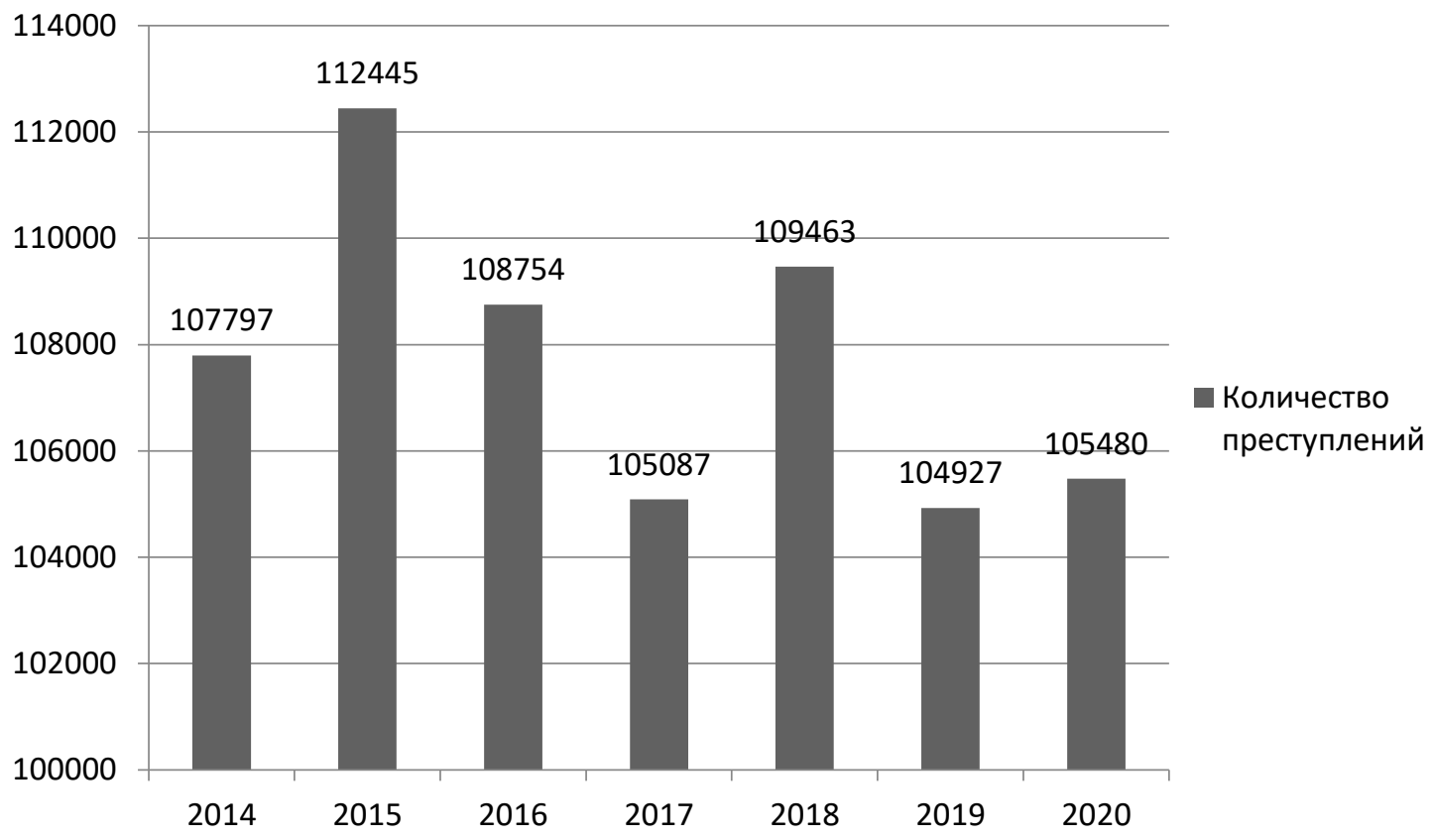

Рисунок 5. Динамика экономических преступлений в России 
работой правоохранительных органов. Но, а что касается киберпреступности, то в развитых странах этот вид преступления все больше и больше набирает обороты, это связано с прогрессивными компьютерными технологиями, которые в России только начинают распространяться [7].

Корпоративные преступления совсем непросто обнаружить, очень много совершенных деяний так и не выявляются. Но все же существуют способы, с помощью которых можно обнаружить признаки или случаи корпоративной преступности. Удивительно, однако зачастую возникают ситуации, когда многие преступления обнаруживаются совершенно случайно, но без работы специалистов здесь не обойтись. Также есть еще несколько способов, с помощью которых выявляется корпоративная преступность, а именно:

- Сообщение сотрудником компании;

- Работа внутреннего аудита;

- Внеплановая ревизия;

- Управление потоками корпоративной информации;

- Выявление в ходе проверки государственных органов.

Что происходит после обнаружения случая корпоративной преступности? Именно с этого момента начинается работа государственных органов. Раскрываемость данных дел достаточно сложный и трудоемкий процесс. Так по данным судебного департамента известно, что в 2020 году за шесть месяцев было рассмотрено 19849 дел, а осуждено всего 10290 человек, 55 оправдано. А что с остальными 9504 делами? Здесь есть два варианта, либо органы просто не смогли обнаружить виновного и разобраться, кто и как совершил преступление, либо же преступникам удалось, каким бы то не было образом уйти от ответственности. Но факт остается фактом, корпоративные преступления наносят большой ущерб компаниям, а если виновный не найден, то организации приходится самой устранять последствия. Гораздо дешевле выявить и предотвратить корпоративную преступность, чем оплачивать ущерб, нанесенный предприятию.

Компании, сталкивающиеся с корпоративной преступностью, могут быть из совершенно разных отраслей. Но чем крупнее эта компания, тем чаще она будет жертвой корпоративных преступлений, и тем больший ущерб будет нести. Но помимо того, что компании теряют свои деньги, также из-за данной преступной деятельности они лишаются своей репутации и имиджа, что не менее пагубно влияет на их дальнейшую деятельность.

Большая доля преступлений приходится на сотрудников среднего звена, а именно $56 \%$. На сотрудников высшего звена приходится $22 \%$. Но при этом большие потери приносят преступления, совершенные именно высшим звеном.

За сотрудниками среднего звена числятся в основном мелкие дела, например, с кассой или бухгалтерской отчетностью. А сотрудники высшего звена умудряются за одно преступление нанести ущерб, сумма которого превысит ущерб от всех мелких преступлений среднего звена вместе взятых. Зачастую, должностные лица совершают данные злодеяния в личных корыстных целях. Здесь уже играют важную роль их характерные качества не как сотрудника, а как человека. Это может быть жадность или карьеризм, патологическая алчность или семейственность. Но также преступления, совершенные высшим звеном, могут быть направлены на улучшение финансового положения собственной фирмы или конкурентной компании [8].

Конечно же, корпоративная преступность не обошла стороной и такую страну как Соединенные Штаты Америки. Здесь, как и в России между преступниками есть разделение на среднее и высшее звено, а именно как это называют на Западе - «синие» и «белые воротнички». Принцип остается тем же, «синие воротнички» - рабочий класс, совершают мелкие и незаметные махинации. Ущерб от них мал, но в сумме дает большую цифру. А вот «белые воротнички» - руководящие должности компании, совершают крупные корпоративные преступления, из-за чего корпорации теряют огромные деньги. Впервые термин «белые воротнички» был дан Э.Сатерлендом в 1939 году. В то время «беловоротничковая» преступность имела достаточную власть, чтобы принимать законы под себя, то есть, создавать себе возможность безнаказанно совершать преступные действия. Сейчас же в США одна из самых эффективных систем борьбы с корпоративной преступностью, что делает эту страну примером для остальных А.А. Вакутин $[9,10]$.

Исходя из вышесказанного, можно сделать вывод, что корпоративная преступность, как в России, так и в США имеет схожие черты. И там и там данная преступная деятельность является распространенным явлением. Но что точно остается различным между этими двумя странами, так это методы борьбы с данного рода пре- 
ступностью.

Для любой компании важной, но в то же время непростой задачей является предотвращение корпоративных преступлений. Для этого на предприятиях вводится такая структурная единица как служба экономической безопасности. И, казалось бы, что с наличием данного отдела можно не волноваться о том, что может появиться какая-то угроза, но все далеко не так гладко. Главная проблема руководства компаний в том, что они абсолютно и слепо доверяют службе экономической безопасности своего предприятия. Зачастую, именно данный отдел является причиной появления корпоративной преступности на предприятии. Ведь логично, что для того чтобы бороться с преступными схемами, необходимо знать, как эти схемы работают, а специалисты отдела экономической безопасности знают это как никто другой. Им ничего не стоит придумать какую-либо новую схему. Поэтому руководству необходимо уделять внимание каждому отделу самостоятельно.

А как же России прийти к такому уровню борьбы с корпоративной преступностью? Начать необходимо с понимания того, откуда исходит данная проблема. Данные преступления совершаются работниками компании. Недобросовестные сотрудники - вот причина всех бед. Но для начала необходимо понять, почему они совершают эти злодеяния? Ответ на этот вопрос достаточно прост. Это могут быть финансовые проблемы, или же обида на начальство, а также некие черты характера, которые подталкивают на совершение преступления. Именно поэтому первое с чего стоит начать борьбу с корпоративной преступностью это создание благоприятного рабочего климата для каждого сотрудника организации.

Вопрос корпоративной этики имеет большое значение абсолютно для каждого предприятия. Корпоративная этика задает формат и тон общения между сотрудниками и руководством. Здесь предписывается должное поведение и отношение к работе, коллегам и начальству. Если руководство найдет правильный подход к сотрудникам в общении с ними, то работники будут доверять начальству и чувствовать себя комфортно [13, 14, 15].

Стоит также учитывать возможные стимулы к работе. Каждый сотрудник должен быть уверен в том, что его хорошая работа будет вознаграждена. И речь идет не о заработной плате. Многие сотрудники очень ответственно подходят к своей работе, но не каждый из них награждается за это, что пагубно влияет на психологическое состояние человека. Именно этот момент становится переломным, и сотрудник начинает совершать корпоративные преступления.

Но и даже все вышесказанное не уничтожит корпоративную преступность, но при этом ее случаи существенно уменьшатся. А вот здесь уже в ход идет работа службы экономической безопасности предприятия. Для того чтобы вести эффективную борьбу с корпоративной преступностью данному отделу необходимо сосредоточить свое внимание не на выявлении совершенных преступлений, а на их предотвращении [16]. Для этого система внутреннего контроля компании должна основываться на базовых принципах. Их вы можете увидеть на рисунке 6.

Для того чтобы создать действительно хорошую систему внутреннего контроля нужно выполнить ряд некоторых условий, а именно:

1. Качественное управление позволит руководству эффективно планировать и контролировать работу компании;

2. Сотрудники должны быть достаточно квалифицированы, а также обязаны следовать должностным инструкциям;

3. Разделение и ротация обязанностей;

4. Качество внутреннего аудита.

Если соблюдать все условия и принципы, то система внутреннего контроля будет работать качественно, а главное результативно [14].

Ну и, конечно же, есть еще одна немаловажная составляющая в борьбе с корпоративной преступностью - законодательство. Экономические преступления развиваются, их становится больше, а их схемы сложнее. Уголовное законодательство Российской Федерации в экономической сфере давно устарело. Пересмотр старых статей и разработка новых увеличит уровень противодействия корпоративной преступности, да и в целом улучшит эффективность борьбы с преступлениями в экономической сфере.

Неким минусом является и то, что в Российской Федерации делами, связанными с корпоративной преступностью, занимаются специальные подразделения МВД России. Нашей стране необходим отдельный орган, который занимался бы расследованием данных преступлений, ведь для этого необходимы специальные экономические знания. Например, в США, данными преступлениями занимается не полиция, а отдельные ведомства, которые находятся в составе министерства финансов [17, 18, 19]. 


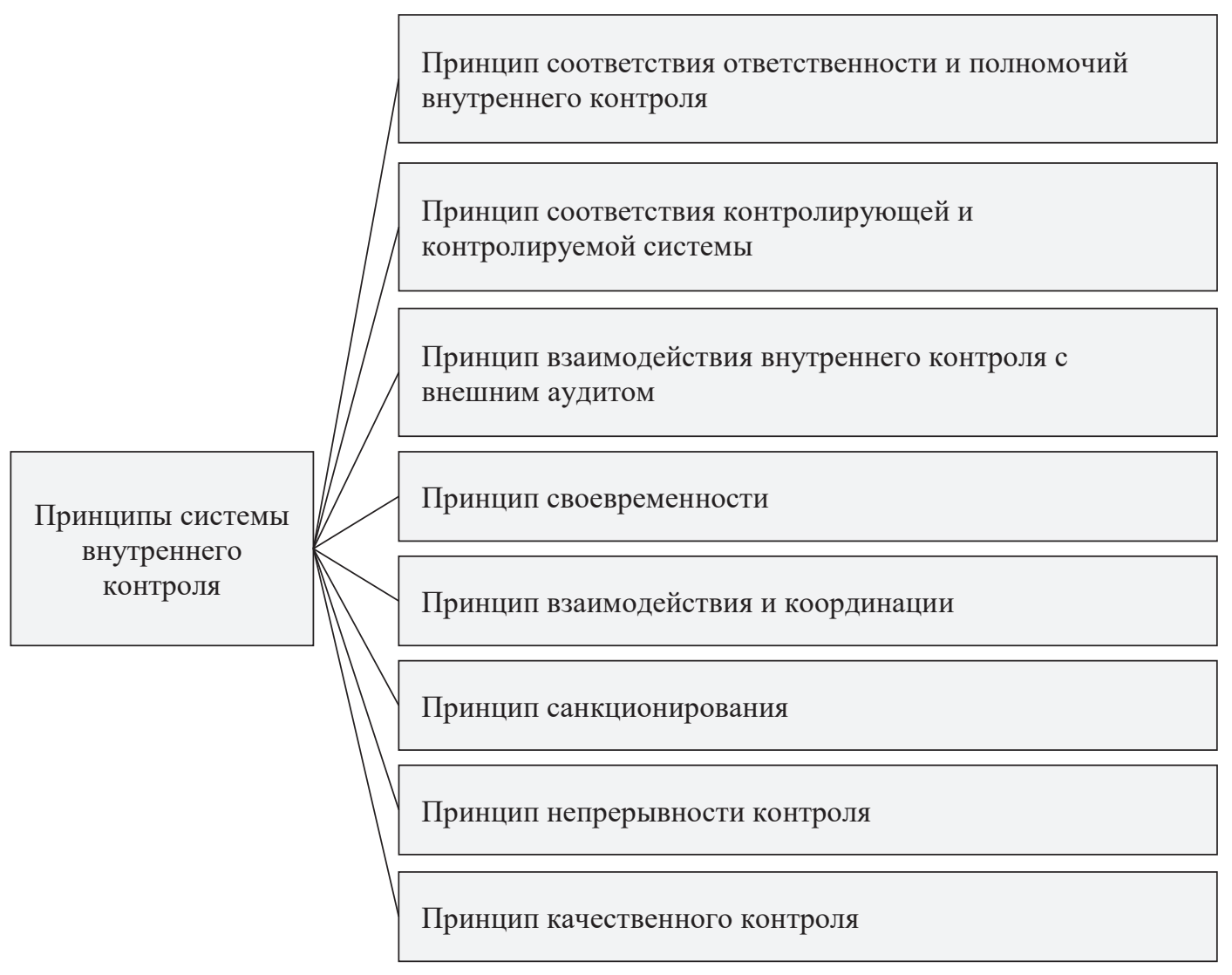

Рисунок 6. Составляющие коррупции

Заключение. Таким образом, можно сделать вывод, что для эффективной и результативной борьбы с корпоративной преступностью компаниям необходимо создать благоприятную рабочую атмосферу среди своих сотрудников, установить доверительные межличностные отношения между сотрудниками и руководством, соблюдать правила корпоративной этики. Также компании должны наладить четкую работу системы внутреннего контроля, чтобы вести пло- дотворную борьбу с корпоративной преступностью и не только. Кроме того, нельзя обойтись без поддержки государства, для этого есть необходимость пересмотреть Российское законодательство, касающееся борьбы с экономической преступностью. если все эти действия будут совершаться в совокупности, то тогда и только тогда Российской Федерации удастся нормализовать ситуацию с корпоративной преступностью и уменьшить ее случаи на уровне страны.

\section{Библиографический список}

1. узнецов А.П. Экономическое преступление и экономическая преступность: соотношение понятий // Юридическая наука и практика: Вестник Нижегородской академии МВД России. 2017. № 3 (39).

2. Федоров А. Ю. Корпоративная преступность. Введение в проблему. Монография. 2019.

3. Садыржанов Б.Э. Противодействие корпоративному мошенничеству в системе экономической безопасности // Экономика. Бизнес. Банки. 2020.03 (41).

4. Изварина Н.Ю., Климина К. В., Рябова Я.А. Корпоративные мошенничества как угроза экономической безопасности хозяйствующих субъектов // Экономика и бизнес: теория и практика. 2020. 10-1 (68).

5. Гулый А.А. Виктимизация юридических лиц - жертв корпоративного мошенничества // Горизонты гуманитарного знания. 2018. № 4. С.

6. Клеймёнов М.П., Пустовит Р. В. Развитие служебной коррупционной преступности // Актуальные проблемы экономики и права. 2018. Т. 12, № 3. С. 594-605. 
7. Кузнецова Е.И., ФилатоваИ.В.Влияние экономической преступности на экономическую безопасность страны в современных условиях // Вестник экономической безопасности. 2018. № 4. (дата обращения: 06.05.2020).

8. лейменов М.П., Клейменов И.М. Детерминация служебной организованной преступности // Вестник Омского университета. Серия «Право». 2019. Т. 16, № 1. С. 156-166.

9. Вакутин А.А. «Беловоротничковая» преступность Э.Сатерленда: теория, не потерявшая актуальности // Вестник Сибирского юридического института МВД России. 2020. № 2 (39).

10. Вакутин А. А. Легалистский подход к определению экономической преступности // Закон и право. 2020.04.

11. Смирнов А.И.Зарубежный опыт деятельности правоохранительных органов по обеспечению экономической безопасности хозяйствующих субъектов (Противодействие транснациональной преступности) // Евразийская адвокатура. 2020.5 (48).

12. Федоров А.В.Экономическая преступность юридических лиц // Юридическая наука и практика: Вестник Нижегородской академии МВД России. 2017. № 3 (39).

13. Протанская Е.С.Профессиональная этика в контексте национальной культуры // Вестник СанктПетербургского государственного института культуры. 2018. № 4 (37).

14. Агеева О.А., Матыцына Ю.Д. Внутренний контроль как инструмент обеспечения экономической безопасности организации на микроуровне // Вестник университета. 2021. № 2.

15. Родионов Д. Г., Зайщев А. А., Дмитриев Н. Д. Интеллектуальный капитал в стратегии обеспечения экономической безопасности Российской Федерации //Вестник Алтайской академии экономики и права. - 2020. - № . 10-2.- С. 156-166.

16. Родионов Д.Г. Управление информационной экономической безопасностью в системе региональной экономики //Мир экономики и права.-2012.- № . 1.-С. 8-13.

17. Кравцова А.Н., Манжосова О. И. К вопросу об уголовной ответственности юридических лиц // Юридический вестник Дагестанского государственного университета. Т. 27. 2018. № 3.

18. Ильин И.В.Виктимологические вопросы борьбы с экономическими преступлениями, совершаемыми в отношении юридических лиц // Юридическая наука и практика: Вестник Нижегородской академии МВД России. 2017. № 3 (39).

19. Шашкова А. В. Криминализация корпоративной ответственности в индустриальном и постиндустриальном обществе // Социально-политические науки. 2018. 